\title{
Body Composition in Iraqi Women With Systemic Lupus Erythematosus
}

\author{
Faiq I. Gorial ${ }^{1}$, Zainab A. Mahmood ${ }^{2} \&$ Sundus Al Obaidi ${ }^{3}$ \\ ${ }^{1}$ Rheumatology Unit, Department of Medicine, College of Medicine, University of Baghdad, Baghdad, Iraq \\ ${ }^{2}$ Department of Medicine, College of Medicine, University of Basrah, Basrah, Iraq \\ ${ }^{3}$ Baghdad Teaching Hospital, DXA Unit, Baghdad, Iraq \\ Correspondence: Zainab A. Mahmood, F.I.B.M.S (Int. Med.), F.I.B.M.S (Rheuma. and Rehab.), College of \\ Medicine, University of Basrah, Iraq. E-mail: zainab_albahrani2000@yahoo.com
}

Received: October 12, 2018 Accepted: December 5, 2018 Online Published: December 13, 2018

doi:10.5539/gjhs.v11n1p63 URL: https://doi.org/10.5539/gjhs.v11n1p63

\begin{abstract}
Background and Objective: SLE is one of systemic diseases, targeting young patients, so we try to study the one of factors that affected these patients.

The aim of our study is to describe the body composition in Iraqi lupus patients, and assess the effect of the disease activity, disease duration, treatment, and patients' social class in development of sarcopenia.

Patients and Method: Sixty women, age > 18years with SLE and 56 matched controls were studied. Disease activity measured by systemic lupus erythematosus disease activity index, and functional status measured by systemic lupus erythematosus quality of life questionnaire. Body mass index, waist circumference measured for patients and controls. Body composition analyzed by dual energy absorptiometry x-ray.

Results: Mean age for patients was $31.75 \pm 10.06$ years, and mean disease duration was $19.62 \pm 10.76$ months. No differences in body mass index, central obesity, lean mass percentage, fat mass percentage, appendicular lean mass index, and bone mineral density between patients and controls. $\mathrm{Z}$ score was lower in lupus patients as compared with controls $(-1.61 \pm 0.8$ for patients, $-1.26 \pm 0.71$ for control, $\mathrm{p}=0.013)$. Treatment with azathioprine found to decrease the risk of sarcopenia $(p=0.046)$. Medical social class and working social class show lower risk for sarcopenia compared to unemployed class $(p=0.003,0.002$ respectively). However disease duration, disease activity, using prednisolone, and functional status had no effect.
\end{abstract}

Conclusions: No significant differences in body mass index, fat mass percentage, lean mass percentage, and appendicular lean mass index in lupus patients and controls. Lupus patients have higher risk to loss their bone density.

Keywords: systemic lupus erythematosus, body composition, sarcopenia

\section{Introduction}

Systemic lupus erythematosus (SLE) is an autoimmune disorder in which organs and cells suffered from damage mediated by tissue-binding autoantibodies and immune complexes. In these patients, autoantibodies are present for years prior to the first clinical symptom (Bevra, 2013). Early ischemic heart disease has appeared as a main cause of morbidity in SLE patients. Increased cardiovascular events can be explained by high prevalence of cardiovascular disease (CVD) risk factors such as metabolic syndrome (Rahman, 1999). In SLE, abdominal obesity as a key-feature of metabolic syndrome with pro-inflammatory and prothrombotic state contributes to atherosclerosis (Yang, 2016). Cytokines such as tumor necrosis factor alpha (TNF-a) are elevated in SLE and these have been linked to loss of fat-free mass (Roubenoff, 1992). Changes in body composition have been reported in SLE patients due to the systemic inflammatory nature of the disease and prolonged corticosteroid therapy. Abnormal body composition phenotypes may represent an additional risk for CVD in SLE patients (Mok, 2008).

\section{Patients and Method}

\subsection{Study Design}

This is an analytical cross sectional study conducted at the Rheumatology Unit in Baghdad Teaching Hospital, 
Medical City, (Baghdad) and Al Fayhaa General Hospital, (Basrah) from December 2016 till June 2017. Ethical approval was taken from Medical department, College of Medicine, University of Baghdad. Participants consent was taken for inclusion in the study.

\subsection{Sample Selection}

A total of 60 consecutive SLE patients were involved in the study. Eligible patients included in the study were: females $>18$ years diagnosed to have SLE according to SLICC classification criteria for SLE (Michelle, 2012). Exclusion criteria included: pregnancy, lactation, ischemic heart diseases, chronic kidney diseases, diabetes mellitus, overlapping inflammatory arthritis or other connective tissue disease. Another 56 -healthy volunteer women non relative to the patients who attended the hospital matched in age were participated in the study as a control group.

\subsection{Clinical and Laboratory Assessment}

Data collection was done using questionnaires and interview. Demographic and clinical features data included: age, sex, body mass index, smoking history, menstruation history, social class, disease duration, diseases activity, quality of life and medications used. SLE disease activity was evaluated using the SLEDAI. The disease activity scored as; no flare if $<3$, mild or moderate flare 3-12, and severe flare if $>12$ (Gladman, 2000). Functional status (disability) was evaluated using the SLE-QoL (Systemic Lupus Erythematosus, 2017) which contain 6 domains including physical functioning, activities, symptoms, treatment, mood and self-image. The response options/scale is 7-point response scale (subsections have different anchors, including "not difficult at all" to "extremely difficult", "not at all" to "extremely troubled", and "not at all" to "extremely often") and recall period for items is 1 week. Scores range from 26-182, with higher values corresponding to worse quality-of-life. Blood and urine samples (complete blood count, C3, C4, antidsDNA, urine for protein, $\mathrm{RBC}, \mathrm{WBC}$ and cast) were collected and the required tests performed in order to calculate SLE disease activity. Social grade depended on the grading system used in National Readership Survey (NRS) (Social Grade, 2017).

\subsection{Anthropometric and Body Composition: Measurements and Definitions}

Standing height (in $\mathrm{cm}$ ), and body weight (in $\mathrm{kg}$ ) were measured, and body mass index (BMI) $\left(\mathrm{kg} / \mathrm{m}^{2}\right.$ ) was calculated. Body weight classified according to BMI to; normal (BMI 18.5-24.9 kg/m²), underweight $(\mathrm{BMI}<18.5$ $\mathrm{kg} / \mathrm{m}^{2}$ ), overweight (BMI 25-29.9 kg/m²), obese (BMI 30-40 kg/m ${ }^{2}$ ), and morbidly obese (BMI $>40 \mathrm{~kg} / \mathrm{m}^{2}$ ). (CDC, 2013) Waist circumference was measured midway between the lower edge of the rib cage and the iliac crest. Abdominal obesity is defined according to International Diabetes Federation criteria for the Asian population 2009 as waist circumference $\geq 80 \mathrm{~cm}$ (Alberti, 2015). Body composition was measured by whole body (except head) DXA using Stratos densitometry and analyzed according to Turkish ethnicity. Fat mass index (FMI) was calculated by dividing body fat mass by the square of the height $\left(\mathrm{kg} / \mathrm{m}^{2}\right)$. Appendicular Lean Mass index (ALMI) was calculated by dividing lean mass of upper and lower limbs by the square of the height $\left(\mathrm{kg} / \mathrm{m}^{2}\right)$. Osteopenia is defined as total $\mathrm{T}$ score -1 to -2.5 , while osteoporosis as total $\mathrm{T}$ score $<-2.5$ or $\mathrm{Z}$ score $<-2$ (Czerwinski, 2007). According to the criteria recommended by Janssen et al (Ian, 2004) low skeletal muscle mass (sarcopenia) was defined as a relative appendicular lean mass index of $\leq 5.75 \mathrm{~kg} / \mathrm{m}^{2}$ in women. Normal lean body mass is $60-90 \%$ of total body weight and usually $<68 \%$ consider as unhealthy.

\subsection{Statistical Analysis}

Normally distributed data presented using their mean and standard deviation, while non-normally distributed data presented as median and interquartile range. Binary logistic regression performed to calculate the odd ratio and it 95\% confidence interval for predicting sarcopenia in SLE patients either in univariate analysis or multivariate analysis. All data analyzed using SPSS version 21, graph Pad Prism and mintab version 18. P value were considered significant if less than 0.05 .

\section{Results}

The mean age of SLE patients was $31.75 \pm 10.06$ year and controls $34.29 \pm 9.93$ year. The mean BMI of SLE patients was $27.72 \pm 6.98 \mathrm{~kg} / \mathrm{m}^{2}$ and controls $28.62 \pm 5.92 \mathrm{~kg} / \mathrm{m}^{2}$. There was no statistical significant differences between SLE patients and controls regarding age and BMI ( $>>0.05)$. Other demographical features between controls and SLE patients were illustrated in Table 1. 
Table 1. Demographic data of patients and controls

\begin{tabular}{|c|c|c|c|}
\hline Variables & SLE patients & Controls & P value \\
\hline Number & 60 & 56 & - \\
\hline Age (year) mean \pm SD & $31.75 \pm 10.06$ & $34.29 \pm 9.93$ & $0.175^{\mathrm{a}}$ \\
\hline BMI group no.(\%) & & & $0.324^{b}$ \\
\hline Under weight & $4(6.7 \%)$ & $1(1.8 \%)$ & \\
\hline Normal & $21(35.0 \%)$ & $16(28.6 \%)$ & \\
\hline Over weight & $15(25.0 \%)$ & $16(28.6 \%)$ & \\
\hline Obese & $15(25.0 \%)$ & $21(37.5 \%)$ & \\
\hline Morbid obesity & $5(8.3 \%)$ & $2(3.6 \%)$ & \\
\hline \multicolumn{4}{|l|}{ Smoking no.(\%) } \\
\hline Never & $58(96.7 \%)$ & $52(92.9 \%)$ & $0.427^{\mathrm{d}}$ \\
\hline Current & $2(3.3 \%)$ & $4(7.1 \%)$ & \\
\hline \multicolumn{4}{|l|}{ Marital status no.(\%) } \\
\hline Married & $29(48.3 \%)$ & $34(60.7 \%)$ & \multirow{2}{*}{$0.182^{b}$} \\
\hline Divorced & $7(11.7 \%)$ & $2(3.6 \%)$ & \\
\hline Single & $24(40.0 \%)$ & $20(35.7 \%)$ & \\
\hline Menstruation no.(\%) & & & $0.526^{\mathrm{b}}$ \\
\hline Active & $50(83.3 \%)$ & $49(87.5 \%)$ & \\
\hline Menopause & $10(16.7 \%)$ & $7(12.5 \%)$ & \\
\hline YSM year (IQR) & $1.5(0.6-9.0)$ & $2(0.5-5.0)$ & $0.659^{c}$ \\
\hline \multicolumn{4}{|l|}{ Social class no.(\%) } \\
\hline Middle class & $3(5.0 \%)$ & $5(8.9 \%)$ & \\
\hline Lower middle class & $4(6.7 \%)$ & $8(14.3 \%)$ & $0.234^{\mathrm{b}}$ \\
\hline Working class & $1(1.7 \%)$ & $3(5.4 \%)$ & \\
\hline Unemployed & $52(86.7 \%)$ & $40(71.4 \%)$ & \\
\hline Waist circumference $(\mathrm{cm})$ mean $\pm \mathrm{SD}$ & $87.98 \pm 14.33$ & $88.89 \pm 11.88$ & $0.712^{\mathrm{a}}$ \\
\hline
\end{tabular}

a Independent $t$ test, $b$ chi square, $c$ Mann Whitney $U$, and $d$ Fisher exact

BMI, body mass index; IQR, interquartile ratio; SD, standard deviation; YSM, year since menopause.

The disease characteristics of SLE patients were presented in Table 2.

Table 2. Disease characteristics of the patients

\begin{tabular}{ll}
\hline Variables & Values \\
\hline Number & 60 \\
SLEDAI mean \pm SD & $19.62 \pm 10.76$ \\
QoL mean \pm SD & $48.20 \pm 16.72$ \\
Prednisolone use, no. (\%) & $57(95.0 \%)$ \\
Prednisolone dose(mg), mean \pm SD & $15.17 \pm 10.73$ \\
Prednisolone use duration(year), median (IQR) & $1.0(0.9-3.5)$ \\
HCQ use, no. (\%) & $23(67.6 \%)$ \\
HCQ dose(mg), mean \pm SD & $334.7 \pm 94.8$ \\
\hline
\end{tabular}


HCQ use duration(year), median (IQR)

AZA use, no. (\%)

AZA dose(mg), mean \pm SD

AZA use duration(year), median (IQR)

MMF use, no. (\%)

MMF dose(g), mean \pm SD

MMF use duration(year), median (IQR)

MTX use, no. (\%)

MTX dose(mg), mean \pm SD

Cyclophosphamide use, no. (\%)

Cyclophosphamide dose $(\mathrm{mg})$, mean $\pm \mathrm{SD}$

$$
\begin{aligned}
& 1.0(1.0-3.0) \\
& 27(45 \%) \\
& 98.1 \pm 25.9 \\
& 1.0(0.7-2.0) \\
& 10(16.7 \%) \\
& 1.6 \pm 0.5 \\
& 1.0(0.6-3.0) \\
& 2(3.3 \%) \\
& 16.3 \pm 5.3 \\
& 4(6.7 \%) \\
& 812.5 \pm 239.4
\end{aligned}
$$

\begin{tabular}{|c|c|c|c|}
\hline Variables & SLE patients & Controls & P value \\
\hline Number & 60 & 56 & - \\
\hline BMI category no.(\%) & & & $0.324^{\mathrm{a}}$ \\
\hline Under weight & $4(6.7 \%)$ & $1(1.8 \%)$ & \\
\hline Normal & $21(35.0 \%)$ & $16(28.6 \%)$ & \\
\hline Over weight & $15(25.0 \%)$ & $16(28.6 \%)$ & \\
\hline Obese & $15(25.0 \%)$ & $21(37.5 \%)$ & \\
\hline Morbid obesity & $5(8.3 \%)$ & $2(3.6 \%)$ & \\
\hline Central obesity no.(\%) & $41(68.3 \%)$ & $39(69.6 \%)$ & $0.879^{\mathrm{a}}$ \\
\hline \multicolumn{4}{|l|}{ Body composition } \\
\hline $\mathrm{LM} \%$ mean $\pm \mathrm{SD}$ & $51.17 \pm 7.16$ & $52.04 \pm 6.16$ & $0.484^{\mathrm{b}}$ \\
\hline \multicolumn{4}{|l|}{ LM group no.(\%) } \\
\hline Normal & $1(1.7 \%)$ & $0(0.0 \%)$ & $1.0 \mathrm{c}$ \\
\hline Unhealthy & $59(98.3 \%)$ & $56(100.0 \%)$ & \\
\hline $\operatorname{ALMI}\left(\mathrm{kg} / \mathrm{m}^{2}\right)$ mean $\pm \mathrm{SD}$ & $6.35 \pm 1.24$ & $6.51 \pm 1.00$ & $0.452^{b}$ \\
\hline \multicolumn{4}{|l|}{ ALMI groups no.(\%) } \\
\hline Normal & $39(65.0 \%)$ & $44(78.6 \%)$ & $0.105 \mathrm{a}$ \\
\hline Sarcopenia & $21(35.0 \%)$ & $12(21.4 \%)$ & \\
\hline $\mathrm{FM} \%$ mean $\pm \mathrm{SD}$ & $37.86 \pm 9.96$ & $39.36 \pm 8.32$ & $0.382^{b}$ \\
\hline \multicolumn{4}{|l|}{ FM group no.(\%) } \\
\hline Normal & $16(26.7 \%)$ & $13(23.2 \%)$ & \\
\hline Overfat & $17(28.3 \%)$ & $12(21.4 \%)$ & $0.610^{\mathrm{a}}$ \\
\hline Underfat & $2(3.3 \%)$ & $1(1.8 \%)$ & \\
\hline Obese & $25(41.7 \%)$ & $30(53.6 \%)$ & \\
\hline
\end{tabular}

AZA, azathioprine; HCQ, hydroxychloroquin; IQR, interquartile ratio; MMF, mycophenolate mofteil; MTX, methotrexate; QoL, quality of life; SD, standard deviation; SLEDAI, systemic lupus erythematosus disease activity index.

The Z score was statistically significantly lower in SLE patients compared to controls, the rest of the variables showed no significant difference between SLE patients and controls as illustrated on Table 3 and Figure 1.

Table 3. Anthropometric, body composition, and BMD characteristics of women with SLE and control subjects 


\begin{tabular}{lccc}
\hline FMI $\left(\mathrm{kg} / \mathrm{m}^{2}\right)$ mean \pm SD & $10.99 \pm 5.20$ & $11.57 \pm 4.33$ & $0.518^{\mathrm{b}}$ \\
$\mathrm{BMD}\left(\mathrm{g} / \mathrm{cm}^{2}\right)$ mean $\pm \mathrm{SD}$ & $0.84 \pm 0.13$ & $0.85 \pm 0.08$ & $0.444^{\mathrm{b}}$ \\
$\mathrm{T}$ score mean $\pm \mathrm{SD}$ & $-1.50 \pm 0.98$ & $-1.23 \pm 0.86$ & $0.113^{\mathrm{b}}$ \\
$\mathrm{Z}$ score mean $\pm \mathrm{SD}$ & $-1.61 \pm 0.80$ & $-1.26 \pm 0.71$ & $0.013^{\mathrm{b}}$ \\
\hline
\end{tabular}

${ }^{a}$ Chi square, ${ }^{b}$ independent $t$ test, ${ }^{c}$ Fisher exact test

ALMI, appendicular lean mass index; BMD, bone mineral density; BMI, body mass index; FM, fat mass; FMI, fat mass index. LM, lean mass; SD, standard deviation.

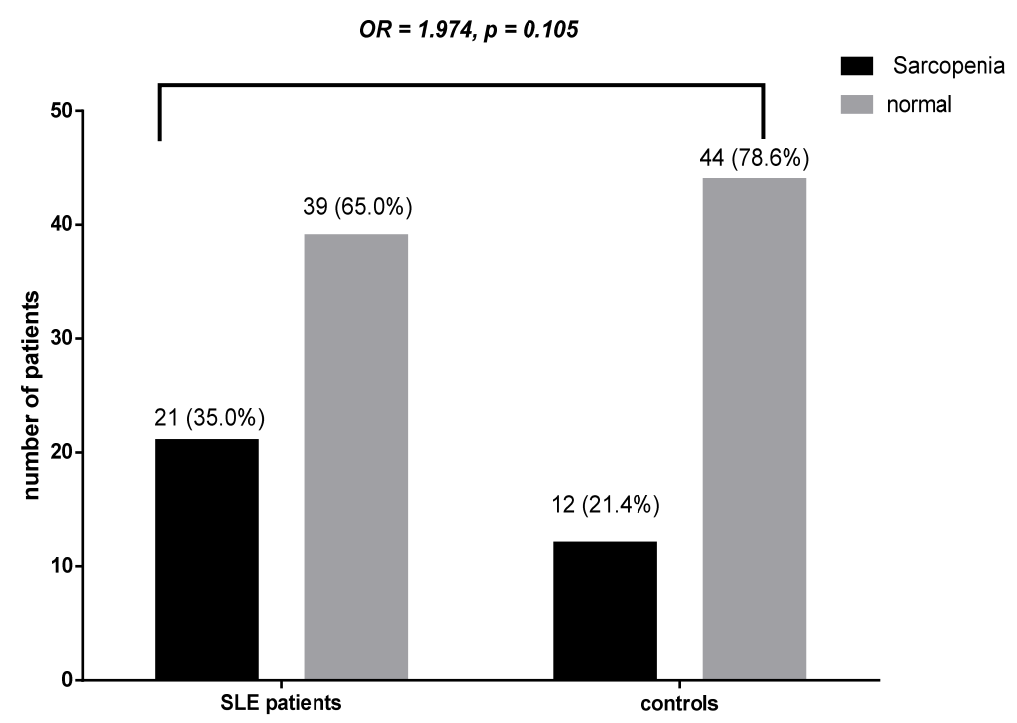

Figure 1. Bar shows abnormal muscle mass (sarcopenia) in SLE patients and controls with P values and OR (odd ratio)

In univariate analysis, patients with low BMI, lower middle class, not using AZA, low LM and high FM\% were associated with sarcopenia. In multivariate analysis, only the use of AZA (reduces risk of sarcopenia) and middle class and working class (reduce the risk of sarcopenia compared to unemployed class) were independent predictors of sarcopenia, the rest of the variables were dependent predictors of sarcopenia, overall the multivariate module had R2 = 0.378 which indicate it has sufficient ability to explain sarcopenia, as shown in Table 4. 
Table 4. Univariate and multivariate binary logistic regression analysis to predict sarcopenia in SLE

\begin{tabular}{|c|c|c|c|c|}
\hline \multirow{2}{*}{ variables } & \multicolumn{2}{|l|}{ univariate } & \multicolumn{2}{|c|}{ multivarate } \\
\hline & OR & P value & OR & P value \\
\hline Age & 0.976 & 0.392 & & \\
\hline BMI & 0.870 & 0.011 & 0.810 & 0.391 \\
\hline Smoking & 1.900 & 0.656 & & \\
\hline single & 1.0 & & & \\
\hline Married & 0.760 & 0.650 & & \\
\hline Divorced & 5000 & 0.088 & & \\
\hline Menopause & 0.773 & 0.717 & & \\
\hline \multicolumn{5}{|l|}{ Social class } \\
\hline Unemployed & Reference & - & Reference & - \\
\hline Middle class & $1.2 \times 10^{-9}$ & 0.002 & $7.3 \times 10^{-10}$ & 0.003 \\
\hline Lower middle class & 5.667 & 0.043 & 2.924 & 0.127 \\
\hline Working class & $1.2 \times 10^{-9}$ & 0.002 & $3.6 \times 10^{-10}$ & 0.002 \\
\hline Disease duration & 1.027 & 0.702 & & \\
\hline PND use & 1.081 & 0.950 & & \\
\hline PND dose & 1.023 & 0.358 & & \\
\hline PND duration & 0.938 & 0.639 & & \\
\hline AZA use & 0.241 & 0.019 & 0.277 & 0.046 \\
\hline SLEDAI & 0.993 & 0.781 & & \\
\hline QoL & 0.996 & 0.792 & & \\
\hline WC & 0.967 & 0.120 & & \\
\hline BMD & 0.278 & 0.571 & & \\
\hline T score & 0.855 & 0587 & & \\
\hline Z score & 0.581 & 0.156 & & \\
\hline LM\% & 1.024 & 0.433 & & \\
\hline FM & 0.970 & 0.172 & & \\
\hline FM\% & 0.951 & 0.031 & 1.122 & 0.140 \\
\hline FMI & 0.912 & 0.119 & & \\
\hline
\end{tabular}

$R 2($ Cox \& Snell $)=0.378$ of the multivariate module.

AZA; azathioprine, BMD; bone mineral density, BMI; body mass index, FM; fat mass, FMI; fat mass index, LM; lean mass, PND; prednisolone, QoL; quality of life, SLEDAI; systemic lupus erythmatosus disease activity index, WC; waist circumference.

\section{Discussion}

The main finding of our study is that; central obesity, unhealthy lean mass, sarcopenia (low ALMI), and high fat mass were similar in both lupus patients and controls with no significant statistical difference ( $p$ value $=0.87,1$, $0.105,0.61$ respectively). We didn't evaluate the dietary intake, a known risk factor for altered body composition in the general population. These results are differ from study of Santos et al. (2011) which done in Caucasians population, when they found that patients with SLE and RA were likely to had abnormal body composition than noninflammatory controls. Also there is a study done by Lilleby et al. (2007) showed that body fat mass in childhood-onset SLE patients was higher and lean body mass was lower than in healthy controls. However our results are corresponding with results of Shamekhi et al. (2017) which done in Iranian population. Of course these difference reflect the social and dietary habits of different society. We found that the presence of sarcopenia in 
lupus patients is not affected by the disease duration nor by the disease activity, also it not affected by corticosteroid treatment (neither the dose nor the duration), however we did not assess muscle performance in our study. These findings are consisting with all above three studies, but in contrast a significant negative effect of corticosteroids on FM and LM had been reported in Kipen et al. (1998) study. On the other hand we found that sarcopenia in lupus patients was significantly more in those who had lower BMI ( $p$ value $=0.011$ ), however low $\mathrm{BMI}$ is found to be dependent risk factor that means BMI itself can't predict the presence the sacropenia (BMI does not discriminate between lean and fat mass), and the sacropenia was more in patients with higher FM\% ( $\mathrm{p}$ value $=$ $0.031)$. Also sacropenia was significantly more in those not treated with azathioprine ( $p$ value $=0.019)$. In our study, treatment with azathioprine was found to be independent protector against sarcopenia. To the best of our knowledge there is no other study showing the effect of azathioprine or other immunosuppressant on development of sarcopenia in lupus patients except for Santos et al. (2011) study who found that FM was not affected by any immunosuppressants. Lower social class across life was associated with higher fat mass in early old age and was also associated with lower lean mass in women after adjustment for fat mass as demonstrated by David Bann et al. (2014). In our study we found a similar results. The sarcopenia was significantly reduced among patients in middle class ( $\mathrm{p}$ value 0.003 , OR $7.3 \times 10^{-10}$ ) and working class ( $\mathrm{p}$ value 0.002 , OR $3.6 \times 10^{-10}$ ), while the reducing effect of lower middle class was dependent on the reduction of other risk factors. We did not study the effect of physical activity on body composition. In present study the bone density presented by total body BMD and T score was lower in lupus patients, however these lower values were insignificantly differ compared with healthy controls ( $p$ value $=0.444,0.113$ respectively). While $Z$ score showed statistically significant lower value ( $p$ value $=0.013$ ) among lupus patients. These results were differ from Abd El-Hady et al. (2017) study, Gilboe et al. (2000) study, and Gracanin et al. (2015) study who found that BMD, T score and Z score all were significantly lower in lupus patients. This difference also may be due to ethnic and society variations and because of bone loss in SLE is heterogeneous and likely a multifactorial process involving both traditional and lupus-related risk factors that may be due to the disease itself or due to its treatment.

In conclusion; there are no significant differences have been observed in patients' BMI, FM\%, LM\%, ALMI as compared with healthy individuals. Treatment with azathioprine may reduce the risk of sarcopenia and lupus patients have a high risk to loss their normal bone density.

\section{Funding}

This research received no grant from any funding agency in the public, commercial or not-for-profit sectors.

\section{Competing Interests Statement}

The Author(s) declare(s) that there is no conflict of interest.

\section{References}

Alberti, K. G., Zimmet, P., \& Shaw, J. (2005). The metabolic syndrome-a new worldwide definition. Lancet. 366(9491), 1059-62. https://doi.org/10.1016/S0140-6736(05)67402-8

Bevra Hannahs Hahn. (2013). Harrison's Rheumatology, Systemic Lupus Erythematosus. New York, NY: McGraw-Hill.

CDC. (2013, January). Overweight and Obesity: defining overweight and obesity. Retrieved from http://www.cdc.gov/obesity/adult/defining.html

Czerwinski, E., Badurski, J. E., Marcinowska-Suchowierska, E., \& Osieleniec, J. (2007). Current understanding of osteoporosis according to the position of the World Health Organization (WHO) and International Osteoporosis Foundation. Ortopedia Traumatologia Rehabilitacja, 9(4), 337-56.

Bann, D., Cooper, R., Wills, A. K., Adams, J., \& Kuh, D. (2014). Socioeconomic position across life and body composition in early old age: findings from a British birth cohort study. $J$ Epidemiol Community Health, jech-2013. https://doi.org/10.1136/jech-2013-203373

Gladman, D., Iba-ez, D., Urowitz, M. B. (2002). Systemic lupus erythematosus disease activity index 2000. Journal of Rheumatology, 29(2), 288-91.

Gudelj Gračanin, A., Marković, I., Lončarević, J., Golob, M., \& Morović-Vergles, J. (2015). Bone Mineral Density In Patients With Systemic Lupus Erythematosus. Reumatizam, 62(2), 16-21.

El-Hady, H. A., Kora, M. A. E. A., Soliman, S. G., Ragheb, A., \& Zahran, E. S. (2014). Study of bone mineral density in patients with systemic lupus erythematosus. Menoufia Medical Journal, 27(3), 556.

Janssen, I., Baumgartner, R. N., Ross, R., Rosenberg, I. H., \& Roubenoff, R. (2004). Skeletal muscle cutpoints 
associated with elevated physical disability risk in older men and women. American journal of epidemiology, 159(4), 413-421.

Gilboe, I. M., Kvien, T. K., Haugeberg, G., \& Husby, G. (2000). Bone mineral density in systemic lupus erythematosus: comparison with rheumatoid arthritis and healthy controls. Annals of the rheumatic diseases, 59(2), 110-115. https://doi.org/10.1136/ard.59.2.110

Kipen, Y., Strauss, B. J., \& Morand, E. F. (1998). Body composition in systemic lupus erythematosus. British journal of rheumatology, 37(5), 514-9. https://doi.org/10.1093/rheumatology/37.5.514

Lilleby, V., Haugen, M., Mørkrid, L., Frøslie, F. K., Holven, K. B., \& Førre, Ø. (2007). Body composition, lipid and lipoprotein levels in childhood-onset systemic lupus erythematosus. Scandinavian journal of rheumatology, 36(1), 40-47. https://doi.org/10.1080/03009740600907881

Michelle, P., Ana-Maria, O., Graciela, S., Alarcón, Gordon, C., Merrill, J. T., Fortin, P. R., ... \& Sturfelt, G. K. (2012). Derivation and Validation of Systemic Lupus International Collaborating Clinics Classification Criteria for Systemic Lupus Erythematosus. Arthritis Rheumatology, 64(8), $2677-2686$. https://doi.org/10.1002/art.34473

Mok, C. C., To, C. H., \& Ma, K. M. (2008). Changes in body composition after glucocorticoid therapy in patients with systemic lupus erythematosus. Lupus, 17(11), 1018-22. https://doi.org/10.1177/0961203308093552

Rahman, P., Urowitz, M. B., Gladman, D. D., Bruce, I. N., \& Genest, J. J. (1999). Contribution of traditional risk factors to coronary artery disease in patients with systemic lupus erythematosus. The Journal of rheumatology, 26(11), 2363-2368.

Roubenoff, R., Ward, L. M., Holland, M. S., \& Hellmann, D. B. (1992). Rheumatoid cachexia: Depletion of lean body mass in rheumatoid arthritis. Possible association with tumor necrosis factor. Journal of Rheumatology, 11(2), 108.

Santos, M. J., Vinagre, F., Silva, J., Gil, V., \& Fonseca, J. (2011). Body composition phenotypes in systemic lupus erythematosus and rheumatoid arthritis: a comparative study of Caucasian female patients. Clinical and experimental rheumatology, 29, 470-476.

Shamekhi, Z., Habibagahi, Z., Ekramzadeh, M., et al. (2017). Body composition and basal metabolic rate in systemic lupus erythematosus patients. The Egyptian Rheumatologist, 39(2), 99-102. https://doi.org/10.1016/j.ejr.2016.10.004

$\begin{array}{lllll}\text { Social } & \text { Grade. } & \text { (2017, } & \text { October). } & \text { Retrieved }\end{array}$ http://www.nrs.co.uk/nrs-print/lifestyle-and-classification-data/social-grade/

Systemic Lupus Erythematosus. (2017, October). Quality of Life Questionnaire. Retrieved from http://oml.eular.org/sysModules/obxOML/docs/id_9/SLEQOL\%20v2_English.pdf

Yang, X., Yang, H., \& Zou, M. L. (2016). Oxidative Stress and Treg and Th17 dysfunction in systemic lupus erythematosus. Oxidative Medicine and Cellular Longevity, 2016, Article ID 2526174, 9. https://doi.org/10.1155/2016/2526174

\section{Copyrights}

Copyright for this article is retained by the author(s), with first publication rights granted to the journal.

This is an open-access article distributed under the terms and conditions of the Creative Commons Attribution license (http://creativecommons.org/licenses/by/4.0/). 